\title{
Powerful knowledge and the curriculum: contradictions and dichotomies
}

British Educational Research Journal, July, 2019 online

Priscilla Alderson

Professor Emerita of Childhood Studies, Department of Social Science, University College London Institute of Education

18 Woburn Square, London WC1H ONR, UK. p.alderson@ucl.ac.uk

\section{Abstract}

The concept of powerful knowledge has central dichotomies and contradictions, which this discussion paper questions. The origins, meaning, purpose and reality of powerful knowledge are considered. Powerful knowledge is based in social realism, and the paper suggests how critical realism could inform more illuminating analyses of knowledge and power. The two versions of realism are compared for their different approaches to dichotomies and dialectic, and to types of knowledge as sacred or profane.

The dichotomies assumed in powerful knowledge theory, which will be reviewed, are: separating concepts from values; informal everyday experience versus formal academic education; separating disciplines versus interdisciplinarity; passive versus active learning and curriculum versus pedagogy; and policies versus theories of power and knowledge. The paper concludes that these dichotomies are unrealistic and unhelpful. If teaching informed by powerful knowledge theory is to benefit students and society, and if knowledge is to be associated with power, it will be helpful to overcome or revoke the dichotomies, which are better understood through dialectical analysis, as shown through the paper.

\section{Introduction: The concept of powerful knowledge}

This paper examines dichotomies and contradictions involved with the concept of powerful knowledge (PK). PK and social realism (SR) cover a range of views among curriculum theorists. Some favour combining principles of disciplinarity and sociality ((Morgan et al. 2019, for example) whereas others work more with dichotomies (for example, Lambert, 2018; Moore, 2013; Moore et al., 2006; Wheelahan, 2010; Young, 008, 2008b, 2012, 2014a, 2014b; Young and Muller, 2016). Throughout this paper 'PK' and 'SR' will mainly refer to the latter group's versions of these broad ranging theoretical approaches. PK theorists perceive

conflict between the formal, codified, theoretical and at least potentially generalising universalising knowledge of the curriculum that students seek to acquire and teachers to transmit, versus the informal, local, experiential and every day knowledge that pupils (or students) bring to school (Young and Muller, 2016:12).

The theorists contend that schools should teach PK, the first kind of formal knowledge, and avoid the second informal kind. 
After all, what else could schools be for, if it were not to provide access to knowledge that children would not have if they were forced to rely...on their families, communities and workplaces (Young, 2012:n.p.).

There are two main reasons for attributing power to certain types of knowledge: epistemically, when the types of knowledge, concepts and methods of thinking are seen as reliable undisputed powerful guides; and politically, when the types are seen to be used by powerful social groups, or to control entry to those groups through qualifying examinations. Both reasons give strong grounds for social justice advocacy that all school students have the right to be taught these advantageous types of knowledge. To deny PK to some groups risks diverting students into lower paid, lower status work, although they will not even be properly prepared for this work, because schools know little about the vocational skills that employers require (Yates and Millar, 2016; Young, 2012, 2014a, 2014b; Young and Muller, 2016).

PK theory emphasises a natural sciences model of knowledge: mathematical precision of fundamental concepts; objectivity and rigour; highly specialised disciplines each with their own strong boundaries, distinct rules and grammar for making judgments; causal and predictive power (for example, Young and Muller, 2016: 115-135). Following critical discussions, "We have extended the meaning and range of "power" from the more obvious predictive powers of the STEM subjects' (science, technology, engineering and mathematics) to include the social sciences, humanities and the arts' (Ibid., 133). Yet instead of assessing the latter for their main concerns, usually seen as the profound questions raised by everyday life, PK theorists tend still to rely on the above natural science models, saying: 'If the social sciences are to retrieve their specializations as the basis of their claims to be a form of powerful knowledge' (this retrieval appears to be uncertain), 'they have to reintroduce the task...of [developing] a socio-epistemic theory of "powerful knowledge" [through] methodological rigour' although they are mainly judged for the weaker extrinsic power, when they are 'policed by the relevant peer community' (Ibid., 132). PK theorists aim to strengthen the social sciences towards the (higher) objective standards of the natural sciences by replacing 'non-specialist contaminants' with highly developed specialist insights In a hierarchy of 'better', more generalisable, reliable, accurate or predictable knowledge, the STEM subjects are highly esteemed as 'the nearest we can get to universal knowledge'. They are in a way 'democratic in that they do not rest on the cultural assumptions of any particular group'. The humanities by relying 'largely on traditions' could 'represent the cultural "knowledge of the powerful" [so that they] compare less and less favourably, on universal criteria, with STEM subjects' (Ibid.: 118-9). The arts (Jane Austen is mentioned) are respected for how they violate conventions and are subversive, and for offering 'a freedom from every day [with] enhanced possibilities and insight into the universal with power to transcend limits' (Ibid., 132-133).The distinction between natural and social sciences might 'turn out to be a red herring' and what matters is the difference between those disciplines that 'are robust enough to gain public trust and those that do not. This is the social heart of powerful knowledge' (Ibid., 130-1). In essence, PK is knowledge that can most extensively and universally be generalised and applied. Everyday experiential knowledge is seen as too contingent. It is assumed, thereby, to narrow students' thinking and therefore to limit their access to real knowledge and the power if can confer.

PK theory is based in social realism, which is said to be influenced by critical realism (Young, 2008; Wheelahan, 2010). The following sections note sociological and philosophical 
traditions from which PK, its meaning and purpose were formed, and then review contrasts between social realism and critical realism, primarily between their thinking either in dichotomies or in dialectic. Dichotomies in PK theory include: sacred and profane; concepts and values; informal everyday experience versus formal academic education; separation of disciplines versus interdisciplinarity; passive versus active learning and curriculum versus pedagogy; and policies versus theories of power and knowledge. The paper concludes that these dichotomies are untenable and unhelpful. PK theorists hope to promote social justice in education but, to achieve their aim, it will be useful to overcome or revoke the dichotomies, which are better understood through dialectical analysis, as shown through the paper.

\section{Dichotomies versus dialectic in social realism (SR) and critical realism (CR)}

This section briefly positions SR and CR in relation to two main traditions in social science in a summary of ideas to be discussed more fully through the paper (also in Alderson, 2013: 26-70). First, interpretivism covers a broad range of theories. Extreme versions treat the world (for example, nature and society, schools and education) as existing mainly or only through our perceptions/constructions, and as contingent on and strongly influenced by social contexts that vary widely over time and place. Extreme versions also regard knowledge as so contingent that it is relativist, without universal truths in knowledge or morality.

$\mathrm{SR}$ and CR both criticise vague and relativist tendencies in interpretivism/ constructionism. Young (2008) asserted the importance of SR, with its clarity about social facts and social justice. The 'realism' in both SR and CR, unlike social constructionism, recognises the existence of reality independent of our thinking and knowing about it. Young and Muller (2016:38) contend that SR, in examining PK's structures, systems and grammars, engages with ideas of certainty, reliability, objectivity and even truth. And SR therefore has an authority to license a whole range of education policies.

The other main social science tradition, positivism, recognises the real world that exists independently of our thinking about it. However, like SR, positivism concentrates on reducing realities into knowledge as concepts, theories, facts (truth claims), images or statistics. CR terms this reducing of the world into ideas, turning real being and doing and things and processes (ontology) into knowledge (epistemology), 'the epistemic fallacy' (Bhaskar, 1998). In contrast, CR anchors thinking into being and keeps exploring the dynamic complexity of the real everyday world. Positivists, social realists and critical realists agree that we can only know the world partly and fallibly, and that progress in knowledge involves working towards, though never reaching, final truths about it. Positivism aims to do so by examining phenomena (anything sensed/observed) and their properties and relations, and by interpreting this evidence through reason and logic to establish verified knowledge. Although today's researchers tend to say they are realists and not positivists (Pawson, 2013), many are still powerfully influenced by neo-positivist approaches.

Positivism, interpretivism and SR work at the empirical level (our experiences, sensed perceptions, thinking, interpreting and remembering) and the actual level (the actual things, people, events and interactions that we sense/observe). CR sees reality in these levels, but also investigates, and considers most important, the origins, working and explanations found at the third deeper unseen real level: powerful influences and causal mechanisms 
that are only apprehended in their effects. These include gravity in physics, genes in biology, and inequalities of social class, gender and race in sociology. SR recognises these in epistemology, in the content of PK and the topics to be taught. Yet it tends to disregard these unseen social causal mechanisms when considering the social-political processes of how curricula are selected, promoted, taught, learned, applied and assessed. This avoidance is intended partly to rely on 'objective' tangible evidence, and partly to avoid relativism or bias (Young, 2014b).

'CR recognises that each element in any dialectic is distinct and partly separate, as well as partly overlapping and interacting. Instead of blurring and merging them together, dialectic works on their interactions, such as between independent existing things (ontology) and our separate knowledge about them (epistemology). CR can contribute to educational research and theorising in two main areas. The first recognises knowledge in the curriculum design and content, its selection and relation to the world (the original world that is studied, and the world in how it might be affected by students' learning when they are adults). The second practical area examines how institutions and other social and cultural structures interact with agents as individuals and groups in education and educational research. There are dialectics within and between the two areas. CR highlights differences between how PK respects deep causal mechanisms in area one, knowledge and the curriculum, but neglects them in area two, the practical socio-politics of PK.

PK theorists aim to promote social justice mainly within present systems. For example, instead of analysing specific inequalities in schools, as CR would do, they refer these to social policy experts (Young and Muller, 2016). SR lacks the 'critical' of critical realism, which supports transformative social change partly by searching for deeper hidden problems and also by respecting the agency of all concerned (Archer, 2007; Bhaskar, 1998, 2008; Gorski, 2013; Porpora, 2015).

SR and CR are very different, and CR attends far more to ontology, such as the being and doing of actual schools, and teachers' and students' interactions with one another, with the curricula, and with the social and natural and everyday contexts and structures around them (Alderson, 2013, 2016). SR and CR both assume that knowledge and curricula are constantly changing and emergent through research, discovery and creativity. However, SR takes the highest, most respected and powerful content or forms of knowledge to be fixed insights with 'objective longevity', which can last over centuries, such as Euclid's theorem, or the universal significance and validity of Weber's theory of the rise of capitalism (Young and Muller, 2016: 129). If PK concepts do change through new analysis, they move even nearer towards final though unreachable constant truths. 'Quantum theory is the most reliable theory of the physical world there has ever been and in that sense it is the nearest we have got to physical reality' (Ibid.: 116). A CR comment on this frequently made point is that the theory brings us nearer to knowing about physical reality (epistemology) but not nearer to the reality itself (ontology), which by being and breathing we are already immersed in. This is another instance of the epistemic fallacy that confuses thinking with being.

Whereas SR tends to separate and isolate ideas and things into fixed dichotomies, CR examines how dynamic realities are connected through dialectic. Dialectic is a valuable though unfortunately unfashionable term (Molyneux, 2007). Dialectic involves developing and resolving conflicts and contradictions through dialogue, and debating through three stages: stating a thesis, arguing a series of antitheses, and reaching a synthesis. Dialectic finds unity between opposites while, as noted earlier, always respecting their distinct differences and not fusing them into a single whole. CR extends traditional dialectic into 
four interacting stages of open-ended recurring cycles (Bhaskar, 2008; Alderson, 2016). Briefly, with the above noted area two, the socio-politics of PK, these attend to:

1. understanding the real seen and unseen world, absences and deeper hidden meanings, historical contexts (such as, theories of different curricula, who designs them and why, students' and society's needs, justice and flourishing);

2. interventions to negate problems, and their effects (how schools actually adopt and provide curricula to serve these needs and overcome ignorance);

3. larger whole contexts (how national and global structures, political economies and inequalities influence schools);

4. transformative change over time (such as how curricula affect personal and political, individual and social progress into the future).

Too much research and policy, like PK theory, works mainly/only at stage two.

SR aims to search 'beyond naturalism' to discover the respective strengths of each separate natural and social science discipline (dichotomies) (Young and Muller, 2016: 127-131). CR is alleged by some SR theorists to share these dichotomies (Oates, 2018: 162). However, CR analyses the unity though not uniformity of the interacting natural and social sciences (dialectic) in The Possibility of Naturalism (Bhaskar, 1998). Naturalism moves beyond scientific reductionism (that treats natural and social research subjects and methods as if they are identical) and it can elucidate the strengths of both the natural and social sciences. Social research about human causal narratives, reasons, motives and values is seen as potentially as credible and valid as the natural sciences can be (Porpora, 2015). To summarise, and as considered below, SR works with dichotomies and a kind of stripping away of complex or ambiguous features to find the unique essence in each isolated concept, phenomenon or discipline in the curriculum. PK theorists also tend to disregard complexity in the socio-politics of designing curricula and their effects. CR dialectic, however, draws together and appreciates the complexity of each concept or phenomenon within their relations to larger totalities. CR connects continuity and change, besides many other seemingly irresolvable dichotomies, in constant dynamic interaction. An example is teachers and students who all learn and change through creative interactions, while retaining many facets of their lifelong personal identities. They interact with the social and cultural in enduring yet changing structures of schools, local communities and larger education systems. They shape their futures within greatly constraining as well as enabling structures, as when they work together to reduce social and ethnic inequalities (Stylianou \& Scott, 2019). CR accepts that they live in real complex open systems of many competing converging influences and largely unpredictable outcomes. Strong predictions are only possible within closed systems with a single powerful influence, which occur in carefully controlled experiments, not in real life. For example, the almost overwhelming force of gravity, competes in open systems with air currents, bird flight and jet engines. PK theory that regards predictable closed-system physics theories as the most powerful knowledge for students to learn, does not help them to understand the real world. A series of PK dichotomies will now be reviewed.

\section{Sacred versus profane}

Durkheim (1912/1995) contrasted knowledge of the sacred versus the profane. He moved religion and the sacred into a higher clearer separate realm from everyday affairs. He saw 
the sacred as an internally consistent world of concepts from which gradually emerged the truth of modern theories in the natural sciences. The profane is found in more contradictory and vague sets of everyday procedures and practices (Young and Muller, 2016:21). Basil Bernstein followed Durkheim's sacred/profane dichotomy, though he removed religion from his analysis of sacred traditions and concentrated on university-based knowledge, contrasting this with everyday knowledge (Moore et al., 2006). He envisaged a 'hierarchical...coherent, explicit and systematically principled structure' of knowledge when the many university disciplines form 'a series of specialised languages with specialised modes of interrogation and criteria for the construction and circulation of texts'. Knowledge 'develops in hierarchies towards ever more general sets of propositions' (Bernstein, 2000: 161-2). The vertical structure of physics produces more and more widely applicable theories in the highest orders of knowledge. Physics knowledge is incremental when each new lesson develops from previous ones, and when new thinkers develop earlier concepts into more advanced theories, in the tradition of 'standing on the shoulders of giants'. There is powerful unanimity and consensus among, for example, $98 \%$ of natural scientists on the effects of climate change (IPCC, 2018). The humanities and social sciences, however, belong to a horizontal structure, where each discipline spreads out to cover more and more specific areas, producing contingent, less generally agreed and less reliable and generalisable knowledge, and lacking the explanatory power of the natural sciences.

PK theorists separate not only Bernstein's vertical from horizontal forms of academic knowledge, but also children's academic learning at school from their everyday social experiences and knowledge, saying that Bernstein believed 'that the natural sciences remain the only model for objective knowledge and knowledge growth' (Young and Muller, 2016: 14). PK theorists aim to enable students to generalise, to form concepts, understand how the world works, and perhaps change it but only after years of learning (Morgan, 2015; Young, 2012, 2014a, 2014b). The political aspect of PK that could help PK-educated students to joinful social groups using PK as 'knowledge of the powerful' has been renounced (Morgan, 2015), qualified (Young and Muller, 2016: 115-135) and firmly disclaimed (Muller and Young, 2019). Yet it is not clear how PK can be powerful, unless its proponents are in advantaged social positions (Lukes, 2008), can think and act effectively, have respected cultural capital (Alderson, under review) or have powerful professional knowledge (Furlong \& Whitty, 2017).

CR theorists say little on the sacred (and its Judeo-Christian tradition of sacrifice), but much on active experiences of power (see below), of spirituality, and concrete (real) utopias (Bhaskar, 2008; Alderson, 2016:135-66).

\section{Concepts versus values}

Young and Muller (2016) aim for impersonal 'value-free' objectivity, intended to rise above social constructionist relativism, and they distinguish the 'power' bestowed by concepts from their moral significance. Yet this risks conflating moral power with authority. Apart from claiming that PK serves social justice, PK theorists tend to avoid examining the complex values within education systems, within PK advocacy, and in how PK should be applied in society. Gouldner (1971) analysed how this kind of Durkheimian functionalism favours utility and efficient functioning. Power is then connected to wealth and control more than to the power of wisdom, justice and compassion. 
However, very young children arguing about the size and justice of pizza portions (Are they fair?) show how we inevitably see values within social concepts and relations (Gopnik, 2010; Gopnik et al., 2001). CR recognises that knowledge and morality are inseparable, and all social facts are value-laden and raise moral questions about whose interests are served, who might be benefitted or harmed, who might gain or lose (Sayer, 2011). Although we cannot attain value-free objectivity, we can aim to be fair and respectful. Students as moral agents need to be able to understand and care about the purpose of their years of schooling in terms of their personal and collective interests (Archer, 2007). They also need to know that they have the right to express their views on their schooling, and adults should respect and take 'due weight' of these views (UN, 1989), such as in sharing with students decisions about which values they hope to promote (Alderson, 2003). Values are a central concern of CR, but not of PK theory.

\section{Informal everyday experience versus formal academic education}

PK theory contrasts children's learning within school and outside school, but is there a great difference? Schools exist mainly to extend and enrich children's knowledge. Multiplication is given as an example of a specialised concept that students only encounter in maths lessons (Young, 2007, 2008). However, an 18-month-old child helping to lay the table knows to match and multiply the number of spoons by the number of diners, and that serving a pizza means dividing it into portions. Vital knowledge of grammar is largely learnt through untaught practice. A 1-year-old who says, 'I dided it' (instead of 'I did it') shows children's sophisticated learning, in every social class, as they gradually work out, with little direct adult explanation, how each verb is tensed and conjugated. PK is assumed to be counterintuitive when teachers help children to cross the 'distance' from their present cognition to acquire highly specific ideas, such as conservation of mass (Oates, 2018: 163). Piaget famously found that children aged under 6-years cannot understand conservation. Yet imaginative experiments with (untaught) 3-year-olds show that they do understand conservation (Donaldson, 1978). Their complex everyday thinking overlaps with academic knowledge and CR deeply respects intuitive everyday knowledge (Bhaskar, 2016). Child psychology theories of gradual development are being challenged. Children are far more mature than is often assumed ( Alderson, 2013b, 2016). Like former ideas of dependent womanhood (Merchant, 1983), many beliefs about childhood are socially constructed, varying greatly over time and place (James and Prout, 1990/1997). Many 'childish' inadequacies are ascribed and then enforced though innumerable social beliefs and behaviours.

Children's school learning is complemented by books and educational games at home enjoyed almost from birth with television programmes, libraries, cinemas, museums, natural spaces, and vast online resources. Children (at English schools) aged from 4-years upwards do homework helped by their parents. Geography teaching is said to give children unique access to PK about space and cities. Young and Muller (2016: 145) agree that pupils who live in London 'know about the part of the city they live in, cops and so on' (a curious sole detail to select). But they consider children need teachers to tell them how cities differ and change. Yet young babies work out meanings of space and proximity (Gopnik et al., 2001), while their sense of distance and of urban and rural life rapidly expands as they travel by pushchair, car and bus. British children who fly to visit relatives in Asia may know far more 
about contrasting cities than their teachers do.

PK theory splits young children from the capacity to think abstract thoughts, as if they can only gradually be introduced to 'academic' concepts by trained school teachers.

Psychologists have detected, through their close analysis of videos of babies' attentive gaze and heart rate, profound understanding from the first days of life. Babies work out time and space, self and others, cause and effect and many other partly abstract, transferable, generalisable concepts (Bloom, 2014; Gopnik, 2010). Babies have to think for themselves long before they can understand verbal explanations. They work out that the babble of speech consists of words, each one with a distinct meaning. An 18-month-old child who sees an elephant and shouts 'doggie', like Linnaeus, is slowly working out taxonomy. Some psychologists conclude that babies think like scientists when they test and try to solve problems with intense concentration and persistence, frustrated when they fail, and joyfully excited when they succeed (Gopnik et al., 2001). Abstract and concrete thinking are interdependent.

All literature, history, human geography and social science are about everyday life, analysed at broad deep levels. History lessons cannot be confined to abstract ideas, but inevitably relate to everyday concerns of nation-building or human rights (Barrett et al., 2018). Theorists who believe it is even possible to set aside the everyday (what is left without it?) do not explain how this can be done. Neither do they say how PK can be reconnected into the everyday. Yet PK has no relation to power unless it works through real daily life. Even vast global policies of trade or peacemaking can only work when majorities cooperate with them by adapting their daily beliefs and behaviours.

Many school students feel bored and alienated from overly abstract knowledge, and many are preoccupied with daily problems such as poverty or violence. For people of any age, to work out how to cope best with daily human experiences and relationships involves the most complex and profound knowledge of all. School curricula which acknowledge this can potentially help children to think through some of their pressing problems and in doing so find energy and concentration that help them to work on more abstract knowledge. Young children's complex thinking is helping researchers to understand constant dialectics between experience, education and intellectual development.

\section{Separating disciplines versus interdisciplinarity}

Within SR, 'we not only differentiate our knowledge from the world of which we have experience, but we differentiate within knowledge as well' (Young and Muller, 2016: 116). PK theorists split apart not only everyday from academic thinking, but also all the disciplines in the natural and social sciences and humanities. These are 'not unitary but plural in series of parallel and incommensurable languages (or sets of concepts)'. They each have separate unique theories or grammars only understood in relation to each other within each distinct discipline. Each is 'incommensurable because it cannot fit into a more general theory' or wider explanatory reach (Young and Muller, 2016: 23). If that is so, and before they formally learn the unique grammars, how can preschool children enjoy books about insects, oceans, cave dwellers, far away cities, machines, Noah's flood and numerous other topics? Young children with Type I diabetes learn from embodied experience of feeling very ill when their blood sugar levels are too high or low, which seriously affects their energy levels. A 4-yearold deeply understood concepts in endocrinology, and why she needed insulin injections: 
'Insulin is the key that turns sugar into energy.' A 5-year-old explained how she did a fingerprick blood test while at a party, to work out if she could eat some cake (Sutcliffe et al., 2004). Everyone starts learning about new disciplines partly by transferring and then expanding knowledge from other disciplines and daily experiences.

To CR theory, all disciplines, natural and social, as well as much everyday knowledge, are commensurable when they rely on literacy and numeracy, knowledge of time and space, historical records, structure and agency, cause and effect, analysis of examples, logical arguments, and the search for explanations and meaning. Arbitrary divisions between disciplines are increasingly challenged in CR theory, and dialectical interdisciplinary work, such as on climate change, is promoted (Bhaskar et al., 2010). In research on climate change, thousands of natural and social scientists not only collaborate but see their complementary work as essential if they are all to gain deeper understanding and progress in every discipline (Hansen et al., 2013; IPCC, 2018, LPI, 2019). To separate scientific from everyday social knowledge, science from society, and simply promote the development of knowledge, removes controls on the kinds of knowledge developed and the power the knowledge actually exerts. Power and decisions about curricula may then all seem abstract, inhuman, apolitical and neutral. And to separate natural science from 'subjective' social sciences, the arts and humanities, law and moral education leaves no means of debating and selecting education and research that can benefit and not harm society. Will PK science promote the arms industry and $\mathrm{CO} 2$ emissions or, informed by the humanities, develop technologies that help to promote peace and justice, and conserve energy, habitats and other species as CR theorists examine ( Alderson, 2016: 17-52; Bhaskar et al., 2010; Sayer, 2011).

\section{Passive versus active learning; curriculum versus pedagogy}

PK theorists expect 'neophyte' children to absorb expert knowledge for years until they are qualified to begin actively to criticise it. PK may be boring, alien and against the students' and their parents' expectations, though the risk of schooling as 'symbolic violence' is dismissed (Young and Muller, 2016: 113). When PK theory sets aside students' own experiences, because they 'do not come to school to know what they already know from experience' (Ibid.), this can exclude what the children are most interested and confident in knowing. Pedagogy then becomes 'what teachers do and get pupils to do' when teachers 'transmit' and 'convey' knowledge (Ibid,: 145). 'Transmit' and 'convey' both suggest distance and a one-way process. This is far from the interpersonal teacher-learner interactions that occur when students do the main unseen work through their acquiring, memorising, critically analysing, reflecting, comparing, and connecting new knowledge into revised and extended former understanding (Mezirow, 2000). These innate capacities are refined through schooling but do not originate, as PK theorists claim, in formal schooling.

There is a paradox in treating school students as agents when they are expected to work hard at learning, and in claiming PK education is their right (Young and Muller, 2016), yet denying or ignoring their agency in their relevant informed views, motives, attention, decision-making and desire to learn. All these capacities, active from birth, are central to lifelong learning and effective teachers nurture them.

Today's citizens are inundated with information/knowledge and their great need is for discerning critical skills to assess it. Young children frequently discuss justice, and 'why?' is a 
favourite word (Bloom, 2014; Gopnik, et al. 2001). 'Why' can ask how effects follow causes, 'Why is it raining?' 'Why' also inquires about purpose and meaning. 'Why do I need to put on a coat/ eat the spinach?' The second 'why' raises questions at two levels, 'How is this meant to benefit me and others or not?' and 'Is the person (offering the coat or food) concerned with my/our interests or not?' These two reasonable questions pervade all children's and adults' learning, and their willingness or reluctance to study.

PK theorists repeatedly say that teachers and parents should know the purpose of schools, what they are for, but they seldom acknowledge students' need to know this too, so that even if lessons are hard or boring, students persist when they believe this is worthwhile as Whitty (2010) and others have shown. CR interest in personhood ( Alderson, 2013; Archer, 2003) can inform analysis of how students' reasons include enthralled wonder and compelling curiosity, passionate interest (preschool expertise in dinosaurs is common), the practical benefit of learning to be independent, enjoyment of learning with friends, and the intrigue of stories, 'what happens next?'. Central to education and social justice are stories, myths and legends, exploited throughout history by great teachers for their compulsive memorable power. Stories have always formed our beliefs (theories) about who we are and how we should live with each other and belong in communities (MacGregor, 2018).

The PK theory assumption, that 'child-led' education (associated with scenario 2, see below) fails, is challenged by many examples within schools (Alexander, 2009; Marshall, 1963). And years of child-led home education that daily follows the children's own inquiries can be highly successful (Thomas, 2008). Success depends on resourceful adults respectfully nurturing children's creative learning. Gopnik (2010) records how babies and parents instinctively embark together on interactive learning, often led by the baby. Maxwell (2005) considers that philosophy, which connects all kinds of knowledge together into wisdom, arises naturally in 5-year-olds' thinking and talking. They search for connections between many aspects of the world, and question and explore possibilities and discoveries. Rather than explicitly teaching children how and what to think, adults encourage conversations that nurture the belief that 'it is proper and desirable for people to resolve problems and conflicts in co-operative, imaginative and rational ways' (Maxwell, 2005: 5). Wisdom goes beyond knowledge and analysis into understanding values, social wellbeing and wanting to resolve pressing social problems. PK dichotomies overlook these vital processes.

To create dichotomies between curricula and personal learning, curriculum theorists versus subject specialists versus pedagogic experts versus teachers versus students misunderstands the nature of learning and of being human. 'Mental activities, unlike physical ones, cannot be carried out unless the people involved in them grasp the point of them, understand their purpose, and make that purpose their own' (Midgley, 1989: 20). Curricula planned by distant experts can be valuable and inspiring. Yet unless account is also taken of the students' and teachers' concerns and their active inter-personal learning, they both risk being oppressed. Their reactions of disaffection and resentment are recorded in numerous reports, which tend to conclude that disaffected students should be blamed and punished for their poor behaviour (Williams, 2018). Social justice, however, is served by working with students to improve curricula and pedagogy in inclusive schools ( Alderson, 2013a, 2016; Alexander, et al., 2009; Ball, 2013; Fielding and Moss, 2011). PK theorists' view, that schools' only purpose is to teach PK, and that this can be undermined by inclusive education (Wheelahan, 2010: 17; Young, 2008b: 10), denies schools' extensive social, civic, moral and childcare responsibilities. 
Within SR's Durkheimian functionalism, 'social justice' implicitly means slightly adjusting the present (unjust) status quo. Injustice may be masked by the offer of equal opportunities, although these can demand too much from disadvantaged students (and teachers), who are then blamed if they fail within social structures of inequality. PK theorists tend to refer this practical problem to pedagogues and avoid discussing political and economic details. It is said to be enough to aim to redistribute knowledge in unequal societies (Oates, 2012: 166). Yet social justice and effective schools involve far more than that, and they depend on curriculum and subject specialists, policy makers, teachers and students all working dialectically together, learning from one another, and reviewing and revising their progress. PK theory involves a dichotomy of knowledge versus skills, warning that 'when the "know what" of conceptual knowledge is replaced by the "know how" of skills, then personal and national social progress, which depends on intellectual specialisation, is threatened' (Young and Muller, 2016: 188). For example, medical school curricula are criticised for concentrating on generic 'can do' skills and neglecting 'high concept' disciplinary knowledge, a process that 'undermines the specialist knowledge base' and its legitimacy (Ibid.: 187). Yet medicine is not a single segregated specialism but embraces physiology, genetics, neurology immunology, pharmacology, etiology, compassionate care and numerous other interacting specialties.

CR sees knowledge and skills as dialectically inseparable when students actively learn, explore, test, apply and practise their new knowledge. They need encouragement to be confident and to persevere. It has long been known that most children begin to fail when knowledge is made artificially abstract (Donaldson 1978; Holt, 1967), with devastating effects. In Zambia, 95 percent of adults reported in one survey that the main lesson their school had taught them was that they were 'brainless' (Serpell, 1993). Learners have different interests, abilities and skills and benefit from a range of disciplines and teaching methods, so that they can all succeed in some ways even if they fail in others. Most work involves both skills and complex knowledge. Surgeons sew; cooking is chemistry experiments; architects work out the daily use of each building; carers help people to cope with complex difficulties; recycling is increasingly complicated and valued. Social justice is not necessarily served by helping brighter students to move up the class system, if the process reinforces class prejudices that disrespect 'vocational' careers, which most school students are destined to have (Reay, 2017), instead of respecting and fairly rewarding all work.

The English literature studied in schools and universities was written for and by people from all classes and vocations: from the first known English poetry by Caedmon the cowherd to the medieval Guilds mystery plays onwards. Monarchs and apprentices alike enjoyed Shakespeare's plays. Although the literature is understood at different levels, there is a spectrum of potential understanding fluctuating across classes rather than clear distinctions. Instead of recognising how authors and readers/audiences meet through their immersion in the profound every day, PK theory misleadingly and unjustly implies that great works of art can only emerge from and be understood within the sacred level of PK theorising. SR theorists address 'the ongoing scandal' of 'the limits of a mass schooling system to induct all children with equal success into elite knowledge traditions' (Young and Muller (2016: 70-76) by proposing three scenarios. The first 'socially divisive one' provides elite knowledge for the few and 'dumbed-down versions of elite knowledge for the masses'. The second 'progressive', 'de-specialised', 'over-socialised' scenario merges school subjects together and favours generic skills instead of respecting PK boundaries and concepts. Its 
'bottom-up' approach is assumed to weaken students' qualifications through teaching which facilitates rather than directs, when 'boundaries between experts versus neophyte learners are weakened' (Ibid., 72). In this seemingly more democratic model, students are offered more choice, but this is discouraged within SR dichotomies. The most favoured future scenario three respects concepts, skills and content in the bounded disciplines of PK as real 'and the social as real (knowledge of the powerful)' in order to educate future experts who will generate new knowledge (Ibid., 74). It is hard to assess how effective scenario three might be when, in further dichotomies, PK curriculum theorists disregard its detailed content, practical working, and potential social and political effects, the topics of the next section.

\section{Policies versus theories of power and knowledge}

The most practical first step in any research is to examine and explain underlying theories. Otherwise, unexamined theories can be most influential, such as the bias of subconscious sexism or class prejudice (Merchant, 1983; Reay, 2016). PK theorists are policy-orientated in their important aims to promote social justice and to recommend improvements in school planning and policies. Yet they tend to separate curriculum theory from practical problems in policy, politics and economics that PK is supposed to address, from the agency of all the adults and students concerned and how agents can apply their knowledge powerfully, and from the intended effects (dialectical stages one, three and four, see above). Explicit explanatory theories of the ontology (nature and function, being and doing) of power and of knowledge are missing, apart from somewhat abstract descriptive concepts of knowledge reviewed earlier.

These omissions result in questionable claims. 'Knowledge is the means by which that social purpose [of justice] is realized' (Wheelahan, 2010: 84). Although knowledge can inform and guide social change, it lacks the agency and actual power to achieve it. PK is said to support 'distributional justice and democracy', when teaching PK gives the working class access 'to participate in society's conversation' (ibid.: 16; Young, 2008b). Yet when the 'conversation' is 'knowledge of the powerful' are all students supposed to join uncritically in World Economic Forum kinds of conversations about neoliberal economics, over-consumption, and denial of climate change?

$\mathrm{CR}$ addresses the two contradictory meanings of power by naming its potentially creative and emancipatory aspects power1, while destructive, coercive aspects are power2, especially in repressive structures and relationships (Bhaskar, 2008: 60). This paper was written before Muller's and Young's paper (2019) was published, which greatly expands their analysis of power. Yet they continue to work mainly in dichotomies, and to reify power and knowledge by treating them as if they are things like packages passed on impersonally to students, with little recognition of students' diversity and agency. Although facts may be exchanged, the transfer of actual power, and of knowledge as understanding, is more complicated. This is because power and knowledge are social and cultural forms and processes that exist through relationships (Archer, 2003; Bhaskar, 1998, 2008). Social power depends on how individual agents develop and apply it. Although personal power and reputation can easily be removed or destroyed by others, these cannot simply be bestowed, though education can help individuals to attain them. Politically, power is conferred by, for example, appointment or election, but appointed or elected leaders may act weakly, 
besides being greatly constrained by their social contexts. Personal power is exerted from within the person rather than bestowed from without. Power works through structural social relationships and positions (Weber, 2013), and involves at least partial control over resources, decisions and over making or resisting change (Archer, 2003, 2007; Bhaskar, 2008). Nelson Mandela studied for a law degree while in prison, after each day of hard labour. His studies later helped to change the world and end apartheid peacefully, but only after he obtained conditions identified by Weber (2013): social status and prestige, membership of a strong economic class and of a political party.

Knowledge is theorised in this paper as our means of understanding the world and ourselves, society and relationships. It does not determine our actions. Instead of the curriculum theory concentration on the teaching of knowledge privileging abstract concepts, CR examines the dialectical contextualising, connecting and synthesising of many different kinds and levels of knowledge, including connections between theory and policy (Bhaskar, 1998, 2008).

If the claimed ends of PK (social justice) are separated from the means intended to promote them (teaching PK) then both may be undermined. Counter-productively, disadvantaged students may be bored and alienated by teaching methods they find coercive and unhelpful (Wheelahan, 2010: 17). Justice and other intended benefits of PK teaching need to be more clearly defined if coherent programmes are to be explained and justified, as others have discussed (Reiss and White, 2013; White, 2018). PK theorists do not explain: how young people transfer from years of habitually being controlled students into becoming responsible adults; what actual effects PK will have, apart from qualifying some groups for more prestigious work; how the educational rationale, to enable children to generalise beyond their own experience (Young and Muller, 2016: 145), connects with practical social justice; why scientific theory is the key to social justice; and why more likely subjects such as politics and civics are relatively ignored.

The means/ends dichotomy complicates harm/benefit assessments of PK theory when it concentrates on the planning stage. Little is said of the practical application or future outcomes, whereas CR's cyclical four stage dialectic (see above) would move through, connect and inter-illuminate all the stages. Expertly planned national curricula can benefit schools, though they are also the lynchpin of national and international highly commercialised testing and league tables systems (Ainley, 2016; Ball, 2013; Scott, 2010). These can help to raise standards, but they also highlight success and failure rates that spur competition between schools, selection of favoured students, exclusion of disadvantaged students and other serious problems (Ainley, 2016). PK theorists' view that schools are not like families or communities (Young, 2014a: 8; Young and Muller, 2016: 105-114) ignores schools' responsibility for their inevitably powerful social and emotional effects on their students, positive or negative. Concern is growing about connections between school exclusions and students' present and future increased liability to problems of poverty, mental illness, racism, drugs, crime and violence (Ford et al., 2018; Welsh and Little, 2018). By ascribing power mainly to abstract knowledge, PK theory overlooks the real power that drives school curricula: business-style competition intended to raise standards but which can result in students studying harder but learning less (Ainley, 2016; Ball, 2013; Ford et al., 2018). Although they allow for extra subjects around the fixed curricula, the theorists ignore how current pressures ensure that resources are increasingly devoted to the competitive core subjects and withdrawn from valuable optional ones. This reduces students' and teachers' choices and agency, besides expecting 'zero-tolerance' levels of compliance unfit 
for educating active democratic citizens. Like the misguided hero in M D Young's (1958) dystopia about meritocracy, PK theory tends to support the benefits of rational social engineering that supposedly rewards merit (in a narrow form of learning), but to overlook the harms and costs to those who do not benefit and to society.

\section{Conclusion}

Do SR and its valorising of PK in vertically structured disciplines offer fruitful and wise advice on planning school curricula? Could CR be more helpful? Leesa Wheelahan (2010) examines similarities between SR and CR: interest in social justice, recognition of independent reality and truth and, she considers, attention to social and cultural structures, although dismissal of these has been noted earlier. Yet there are clear differences between CR and SR. Porpora (2015: 188-208) identifies basic commitments of CR to explicit analysis of: conscious agents, social structures, qualitative and quantitative methods, underlying theories, truth, and values. PK theory tends to devote little attention to:

- the conscious intentional agency of teachers and students, their experiences, motives, views and interests;

- their interactions with social structures;

- qualitative and quantitative research reports that would explain and assess the social working and impact of PK curricula;

- metatheory, or explicit analysis of assumed theories to explain the specific detailed meanings of power and of knowledge, how far and why knowledge actually exerts power and with what effects;

- truth in social life, not only in PK;

- values, apart from a quite vague claim to promote social justice.

There are also problems of the epistemic fallacy when actual things and events, unseen powerful interacting causal influences, dynamic processes of personal and political change, and ontology (being and doing) are largely collapsed into epistemology (knowledge, PK). This paper has reviewed SR's tendency to set up unrealistic and unhelpful dichotomies and contradictions: between disciplines, between the sacred versus the profane, and concepts versus values, everyday versus academic thinking, passive versus active learning, curricula versus pedagogy and theories versus policies. The dichotomies weaken analysis, and the possibility of recommending curricula that can help school students in their learning and thinking, especially those most in need of help. The dichotomies do not help to advance social justice by enabling many more students to fulfil their potential.

Ways in which CR concepts could inform future curriculum theorising have been suggested. They would revise these dichotomies into dialectical analysis of transformative change at all the interconnected levels. They would take due account of the immensely complex interrelated concerns of personal learning, teacher-student interactions, planning and provision of education systems, societies' present and future flourishing, and the associated benefits (and potential harms) to all the individuals concerned. They would also frame education policies within dialectic progress from oppressive power2 structures towards fulfilling power1 relations and experiences. 


\section{Acknowledgments}

I am grateful to the two very helpful anonymous reviewers who advised on major revisions to this paper.

\section{References}

Alderson, P. (2003). Institutional Rites and Rights (London, Institute of Education).

Alderson, P. (2013a). Learning and Inclusion (London, Routledge).

Alderson, P. (2013b). Childhoods Real and Imagined (London, Routledge).

Alderson, P. (2016). The Politics of Childhoods Real and Imagined (London, Routledge).

Alderson, P. (under review) Powerful knowledge, myth or reality? Four necessary conditions for knowledge to be associated with power.

Ainley, P. (2016). Betraying a Generation (Bristol, Policy).

Alexander, R. et al. (eds.) (2009) The Cambridge Primary Review Research Surveys (London, Routledge).

Archer, M. (2003). Structure, Agency, and the Internal Conversation (Cambridge, Cambridge University Press).

Archer, M. (2007). Making our way through the world (Cambridge, Cambridge University Press).

Ball, S. (2013) Education, Justice and Democracy (London, CLASS).

Barrett, B., Hoadley, U. \& Morgan, J. (Eds.), (2018) Knowledge, Curriculum and Equity: Social Realist Perspectives (London, Routledge).

Bernstein, B. (2000). Pedagogy, Symbolic Control and Identity Revised edition by M. Lanham (London, Rowman \& Littlefield).

Bhaskar, R. (1998). The Possibility of Naturalism (London, Routledge).

Bhaskar, R. (2008). Dialectic: The Pulse of Freedom (London, Routledge).

Bhaskar, R. (2016) Enlightened Common Sense (London, Routledge).

Bhaskar, R., Frank, C., Hoyer, K., Næss, P. and Parker, J. (eds.) (2010.) Interdisciplinarity and

Climate Change (London, Routledge).

Bloom, P. (2014). Just Babies: The Origins of Good and Evil (New York, Broadway Books).

Donaldson, M. (1978). Children's Minds (Edinburgh, Fontana).

Durkheim, E. (1912/1995). The Elementary Forms of the Religious Life. Trans, K. Fields (New

York, Free Press).

Fielding, M. \& Moss, P. (2011). Radical Education and the Common School (London,

Routledge).

Ford, T., Parker, C., Salim, J. \& Goodman, R. (2018). The relationship between exclusion from school and mental health, Psychological Medicine, 48, 629-41.

Furlong, J., \& Whitty, G. (2017). Knowledge and the Study of Education (Oxford, Symposium Books).

Gopnik, A. (2010). The Philosophical Baby. (London, Picador).

Gopnik, A., Meltzoff, A. \& Kuhl, P. (2001). How Babies Think (London, Phoenix).

Gorski, P. (2013). What is critical realism and why should you care? Contemporary Sociology, 42: 658-70.

Gouldner, A. (1977). The Coming Crisis in Western Sociology (London, Routledge).

Hansen, J., Pushka, K., Sato, M. \& 15 others. (2013). Assessing 'Dangerous Climate Change', http://www.plosone.org/article/info\%3Adoi\%2F10.1371\%2Fjournal.pone.0081648. 
Holt, J. (1967). How Children Learn (London, Penguin).

IPCC - Intergovernmental Panel on Climate Change. (2018). Global warming of $1.5^{\circ}$,

https://report.ipcc.ch/sr15/pdf/sr15 spm final.pdf

James, A. \& Prout, A. (1990/1997). Constructing and Reconstructing Childhood (London,

Routledge/Falmer).

Lambert, D. (2018). Teaching as a research-engaged profession, London Review of

Education, 16: 357-370.

LPI. (2019). https://www.Ipi.usra.edu/education/explore/ice/background/allAboutWater/.

Lukes, S. (2008) Moral Relativism (London, Profile).

MacGregor, N. (2018). Living with the Gods (London, Allen Lane).

MacIntyre, A. (1981). After Virtue (Notre Dame, IN, University of Notre Dame Press).

Marshall, S. (1963). An Experiment in Education (Cambridge, Cambridge University Press).

Maxwell, N. (2005). Philosophy seminars for five-year-olds, Learning for Democracy, 1: 71-7.

Merchant, C. (1983). The Death of Nature (London, Harper \& Row).

Mezirow, J. (2000). Learning as Transformation (San Francisco, Jossey Bass).

Midgley, M. (1989). Wisdom, Information and Wonder (London, Routledge).

Molyneux, J. (2007). The Point if to Change It (London, Bookmarks).

Moore, R. (2013). Social realism and the problem of the problem of knowledge in the sociology of education, British Journal of Sociology of Education, 34: 333-353.

Moore, R., Arnot, M., Beck, J. \& Daniels, H. (2006). Knowledge, Power and Educational Reform:

Applying the Sociology of Basil Bernstein (London, Routledge).

Morgan, J. (2015). Michael Young and the Politics of the School Curriculum, British Journal of

Educational Studies, 63:5-22.

Morgan, J., Hordern, J. \& Hoadley, U. (2019) On the politics and ambition of the 'turn',

Curriculum Journal, 30: 105-24.

Muller, J. \& Young, M. (2019) Knowledge, power and powerful knowledge, Curriculum

Journal, 28: 1-19.

Oates, T. (2018) Powerful knowledge: moving us all forwards or backwards? In Guile, D, Lambert, D. and Reiss, M. (eds) (2018) Sociology, Curriculum Studies and Professional Knowledge (London, Routledge, 157-168).

Pawson, R. (2013) The Science of Evaluation. (London, Sage).

Porpora, D. (2015). Reconstructing Sociology (Cambridge, Cambridge University Press).

Reay, D. (2017). Miseducation (Bristol, Policy).

Reiss, M. \& White, J. (2013). An Aims-Based Curriculum (London, Institute of Education Press).

Sayer, A. (2011). Why Things Matter to People (Cambridge, Cambridge University Press).

Scott, D. (2010). Education, Epistemology and Critical Realism. London: Routledge.

Serpell, R. (1993). The Significance of Scholarly Life Journeys in an African Society

(Cambridge, Cambridge University Press).

Stylianou, A. \& Scott, D. (2019) Social and Ethnic Inequalities in the Cypriot Education

System. London: Routledge.

Sutcliffe, K., Sutcliffe, R. \& Alderson, P. (2004). Can very young children share in their

diabetes care? Paediatric Nursing 16: 24-26.

Thomas, A. (2008). How Children Learn at Home (London, Continuum).

UN - United Nations, (1989). Convention on the Rights of the Child (New York: UN).

Weber, M. (2013). Economy and Society (Oakland, CA, University of California Press).

Welsh, R. \& Little, S. (2018). The school discipline dilemma, Review of Educational Research,

https://doi.org/10.3102/0034654318791582. 
Wheelahan, L. (2010). Why Knowledge Matters in the Curriculum (London, Routledge).

White, J. (2018). The weakness of 'powerful knowledge', London Review of Education, 16:325-35.

Whitty, G. (2010) Revisiting School Knowledge, European Journal of Education, 45: 28-45

Yates, L. \& Millar, V. (2016). 'Powerful knowledge' curriculum theories and the case of physics. The Curriculum Journal, 27: 298-312.

Young, M. (2008). Bringing Knowledge Back In (London, Routledge).

Young, M. (2008b). From constructivism to realism in the sociology of the curriculum', Review of Research in Education, 32: 1-28.

Young, M. (2012). The curriculum - An entitlement to powerful knowledge: a response to John White, www.newvisionsforeducation.org.uk/about-the-group/home/2012/05/03/thecurriculum-'an-entitlement-to-powerful-knowledge'-aresponse-to-john-white/

Young, M. (2014a). What is a curriculum and what can it do? Curriculum Journal, 25:7-13.

Young, M. (2014b). Powerful knowledge as a curriculum principle, in: Young, M., Lambert, D., Roberts, C. and Roberts, M. (eds) Knowledge and the Future School (London, Bloomsbury).

Young, M. \& Muller, J. (2016). Curriculum and the Specialization of Knowledge (London, Routledge).

Young, M. D. (1958). The Rise of the Meritocracy? (London, Pelican). 